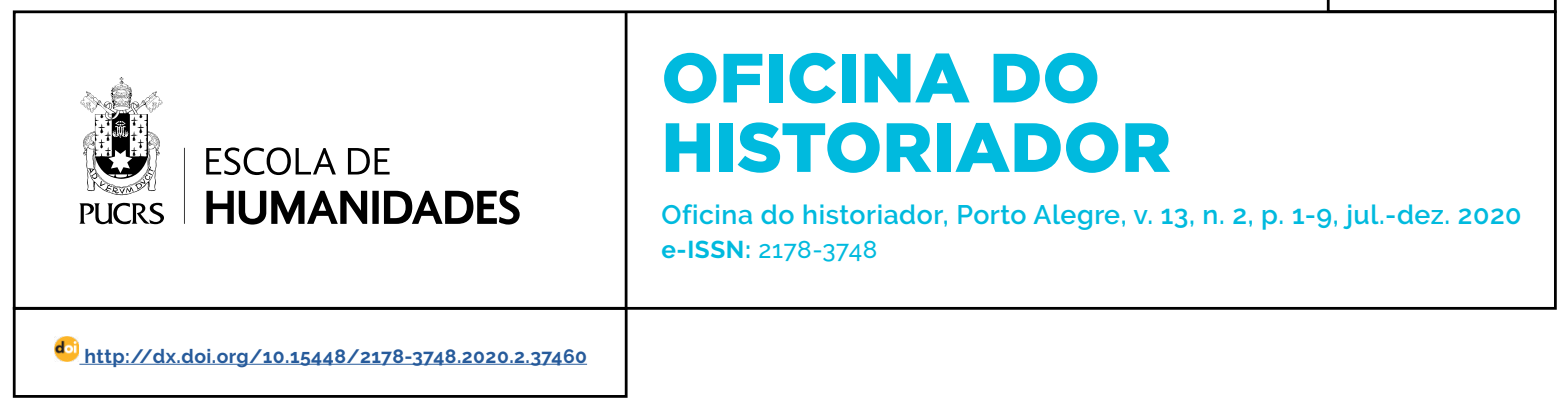

SEÇÃO: ENTREVISTA

\title{
Entrevista com Robert Darnton (Tradução)
}

\author{
Interview with Robert Darnton (Translation)
}

\section{Lucas de Oliveira \\ Klever $^{1}$ \\ orcid.org/0000-0001-5376-9014 \\ lucas.klever@acad.pucrs.br}

Recebido em: 26 mar. 2020. Aprovado em: 4 abr. 2020. Publicado em: 21 dez. 2020.

\section{(c) (1)}

Artigo está licenciado sob forma de uma licença Creative Commons Atribuição 4.0 Internacional.

\section{Introdução}

Esta entrevista foi originalmente publicada em 21 de junho de 2004 , pelo professor Marek Tamm na revista Vikerkaar, ${ }^{2}$ Estônia. O professor é titular da disciplina de História Cultural na Universidade de Tallinn. A sua entrevista, apesar de datada, apresenta grande contribuição das obras e trajetória de Robert Darnton, que é um historiador cultural, reconhecido pelas suas obras do lluminismo, da Revolução Francesa e dos estudos da França do século XVIII. Darnton foi professor na Universidade de Princeton até 2007 e, atualmente, trabalha na direção da Biblioteca da Universidade de Harvard, EUA. A entrevista, nunca traduzida para o português, relata a influência positiva do jornalismo na trajetória do entrevistado. Também demonstra como os interesses de Darnton foram mudando ao longo do tempo, além de explicar como chegou nas fontes de obras famosas, como O Grande Massacre dos Gatos, 1984. Outras questões pontuais, mas não menos importantes são discutidas: a história dos livros; a relação história e antropologia; o debate com seu amigo Roger Chartier; o trabalho com as fontes; a relação do historiador com o contemporâneo. Espero que tenham uma boa leitura!

Robert Darnton resume a sua visão sobre as novas formas eletrônicas de publicação e os seus efeitos nas livrarias, jornais, universidades e nos caminhos da leitura de livros. Como um historiador preocupado com a história do livro, Darnton conecta as formas históricas de leitura e as publicações de livro com as últimas revoluções trazidas pela internet ${ }^{3}$

Desde o início, você esteve fascinado não só pela história, mas também pelo jornalismo. Seu pai trabalhou para o The New York Times e já aos quatro anos de idade, você escreveu sua primeira "contribuição" para esse jornal. Mesmo depois da sua graduação, você optou pelo trabalho de repórter no New York Times, em vez da docência.

Pontifícia Universidade Católica do Rio Grande do Sul (PUCRS), Porto Alegre, RS, Brasil.

Entrevista original, em inglês, disponivel em: https://www.eurozine.com/interview-with-robert-darnton/. Acesso em: 26 mar. 2020. A entrevista conta com autorização de tradução fornecida por Marek Tamm. [This article was first published in English in Eurozine and contributed by Vikerkaarl.

O texto em negrito será a pergunta realizada por Marek Tamm. E a resposta de Robert Darnton, sem negrito, logo abaixo. 
Embora você tivesse escolhido história, algum tempo depois você ainda estava cooperando de perto com o jornalismo, particularmente com o The New York Review of Books. Provavelmente, o seu desejo característico de comunicar os resultados da sua pesquisa para a maior audiência possivel, vem da sua experiência com o jornalismo, também. Na sua introdução do Beijo de Lamourette ${ }^{4}$ você colocou diretamente a questão: "Por que a história não deveria ser tão interessante quanto o homicídio?"

Sim, eu concordo que o jornalismo sempre foi importante para mim, primeiro como uma questão de familia e depois como um objeto de estudo. Desde os meus primeiros anos, eu me senti predestinado para ser um repórter de jornal, principalmente porque meu pai foi morto como um correspondente de guerra durante a Segunda Guerra Mundial e, conscientemente ou não, eu pensei que deveria seguir seus passos largos. (Nós não usamos o nobre termo "jornalista" na minha familia; "repórter" conotava a honesta "caminhada"5 de um homem que seguia eventos ao nivel da rua). Depois de trabalhar na "escola do jornalismo", eu passei pelo treinamento básico no The Newark Star Ledger, onde eu cobri a sede da polícia e aprendi o que o jornalista considerava ser "noticias". Depois disso, eu trabalhei parte do tempo para o The New York Times e finalmente me juntei ao The Times, depois de completar meu Ph.D. em Oxford. De volta a Nova York, eu me encontrei cobrindo mais roubos armados e assassinatos. Mas depois de várias semanas na sala de imprensa da sede da polícia, o jogo de "polícia e ladrão" tornou-se obsoleto. Todas as notícias começaram a parecer do mesmo jeito, a corresponder a padrões estilisticos e eu ansiava retornar aos arquivos. Eu costumava ir para a sede da polícia com a "Civilização da Renascença" de Burckhardt, escondida dentro de uma cópia da Playboy, para que os outros repórteres não suspeitassem das minhas secretas tendências intelectuais. Finalmente, eu sai do The Times, e eu preciso dizer que como historiador, eu vivi feliz para sempre depois disso. Mas eu ainda acredito que historiadores devem escrever de uma forma que possa ser entendida pelos leitores comuns. Eu até me aventuraria a dizer que eles deveriam tornar a história um prazer, não um entretenimento trivial, é claro, mas em vez disso uma experiência satisfatória, uma que amplia o entendimento da condição humana.

Ao longo das décadas, a sua pesquisa foi focada no Iluminismo francês. Ainda, se os historiadores têm como regra, serem interessados nas grandes ideias dos grandes pensadores do periodo, você tomou um interesse pela "vida-debaixo", ${ }^{6}$ em vez de; você tentou escrever uma espécie de história intelectual dos "não-intelectuais".7 0 que, de qualquer forma, poderia ser o papel desses autores pouco conhecidos e vendedores de livros - os pauvres diables, como Voltaire os chamou - no movimento lluminista, no geral? O seu estudo do Iluminismo visto debaixo, tal como era, permitiu que você reavaliasse o período?

Como eu primeiro formulei, a noção de estudar o lluminismo "debaixo" levou a alguma confusão, porque de fato minha pesquisa consistia nos escritores no geral, quer fossem ou não, alinhados com as philosophes. Em retrospectiva, eu pensei que estava tentando desenvolver uma sociologia da autoria, não uma nova interpretação do Iluminismo. Desde o meu primeiro trabalho no objeto, que volta para os anos de 1960, eu tenho tentado realizar mais pesquisa sistemática na população inteira do mundo literário durante o

DARNTON, Robert. The Kiss of Lamourette. Reflections in Cultural History. New York: W.W. Norton, 1990, p. XVIII-XIX.

"shoe-leather", a expressão não possui uma tradução semelhante no português. Nesse caso, provavelmente, o autor estava fazendo uma comparação entre os "repórteres genuinos" que saíam as ruas para caminhar, investigar, entrevistar etc.; vestindo o "couro dos seus sapatos" para conseguir um bom relato. Isso seria o oposto da mídia moderna, onde as pessoas procuram online por dados e transformam em jornalismo.

6 DARNTON, Robert. The literary underground of the Old Regime. Cambridge: Harvard University Press, 1982.

DARNTON, Robert. Gens de letres, gens du livre. Paris: Odile Jacob, 1992.

DARNTON, Robert. Two paths through the social history of ideas. In: MASON, Haydn Trevor. The Darnton debate: books and Revolution in the eighteenth century. Oxford: Voltaire Foundation, 1999. 
século dezoito, da sua composição e das suas mudanças ao longo do tempo. Eu continuo a acreditar que escritores que chegaram à idade adulta nos anos 1770 e 1780 foram inspirados pelos exemplos dos grandes philosophes. Eles frequentemente queriam entrar para a "igreja" de Voltaire e "ferviam" de ressentimento quando fracassavam em atingir as primeiras pontuações da República de Letras. Muitos deles se tornaram jacobinos. Mas não há relação correlata entre a ambição frustrada e o jacobinismo. Alguns hack writers ${ }^{8}$ se tornaram contrarrevolucionários. Barnabá Farmian de Rosoi é um bom exemplo: um prolífico hack do Antigo Regime, que se tornou um jornalista oficial durante a Revolução (Ele merece uma biografia).

Rua Grub (Grub Street) era um lugar complexo e merecia ser estudado em toda sua complexidade, sem sucumbir ao psicologismo reducionista. Isso certamente abasteceu muitas tropas de choque do lluminismo: jornalistas; panfletários; polemistas; auxiliares e intermediários de todos os tipos. Se você pensar no lluminismo como primariamente uma tentativa de espalhar a luz, esses pequenos jogadores parecem importantes -para eles-, eles foram os que fizeram a vulgarização e a propagandização. Verdade, Voltaire, ele mesmo, manipulou a mídia do seu tempo. Ele era um mestre em dominar a opinião pública. Mas ele poderia não ter sucedido sem os soldados rasos que ele foi capaz de inspirar e mobilizar. Ao estudar as atividades, alguém pode ver como o Iluminismo funcionava na sua profunda fabricação da sociedade. Essa é a direção que eu tentei levar os estudos do lluminismo, que pode ser chamada de história social das ideias
Um dos campos da escrita da história, que você promoveu ativamente por mais de 30 anos é a "história do livro". ${ }^{9}$ Nos anos recentes, os seus interesses se ampliaram, de qualquer forma, em vez da história dos livros você se interessou pela "história das comunicações"10 no geral, como testemunhamos também pelo seu último livro, "Dentes Falsos de George Washington". Como você poderia descrever o desenvolvimento dos seus interesses nessa direção em particular?

Eu penso que a sua descrição é bastante adequada. Ao estudar a história dos livros, eu tive que confrontar a história da leitura, para procurar as conexões entre a difusão da literatura e a formação de fenômenos misteriosos, que nós chamamos de opinião pública. Isso tornou-se claro ao longo do caminho, que os livros eram uma das muitas mídias daquele tempo. De fato, os textos impressos frequentemente incorporam fofocas da oralidade, sons, "ruidos públicos" - e depois transmitiu mensagens que reentraram no circuito da oralidade da comunicação através da discussão ou da leitura em grupos. Então, sim, eu penso que a história do livro se abre em uma larga história da comunicação. Graças a mídia moderna, nós podemos estudar modos antigos de comunicação de novas formas. Depois de descobrir centenas de sons improvisados sobre os eventos atuais no manuscrito "chansonniers" de 1740, eu encontrei manuscritos com notas musicais para os sons. Um amigo meu, Hélène Delavault, que é um excepcional cantor de cabaré em Paris, concordou em cantá-los. Agora eles podem ser ouvidos numa versão eletrônica de um dos meus

\footnotetext{
8 Expressão inglesa para escritor contratado para realizar trabalhos secundários, muitas vezes de carácter provocatório, em periódicos de segunda linha ou para revistas especulativas ou satíricas. Um hack writer é muitas vezes contratado para criticar (destrutivamente) um filme, um espetáculo de teatro, um concerto musical, ou um livro, por exemplo. A literatura panfletária conheceu escritores pagos à tarefa pelo menos desde o século XVII. O século XVIII conheceu alguns escritores-tarefeiros célebres como Daniel Defoe, Jonathan Swift e Ben Johnson, por exemplo, que foram hack writers durante as suas vidas, sobretudo para participarem nas diferentes polêmicas e discussões politicas, morais e culturais em que se envolveram nas páginas de periódicos da época. Nos dias de hoje, o conceito corresponde à ideia de freelance writer.

9 DARNTON, Robert. What is the history of books. Daedalus, Cambridge, v. 111, n. 3. p. 65-83, 1982

DARNTON, Robert. The Kiss of Lamourette Reflections in Cultural History. New York: W.W. Norton, 1990, p. $107-135$

DARNTON, Robert. Histoire du livre Geschiche des Buchwesens: na agenda for comparative History. Publishing History, n. 22, p. 33-41, 1987. DARNTON, Robert. Scholarship and Readership: New directions in the History of the Book. In: Books and prints, past and future. New York: The Grolier Club, 1984.

10 DARNTON, Robert. La France, ton café fout le camp! De l'histoire du livre à l'histoire de la communication. Actes de la recherche em sciences sociales, v. 1, n. 100, p. 16-26, 1993.
} 
ensaios - em History Cooperative. ${ }^{11}$ Isso soa brega, mas agora nós podemos fazer a história cantar.

Seria difícil imaginar o trabalho da sua pesquisa sem os arquivos da Société typographique de Neuchâtel, descobertos por você mesmo no começo dos anos 1960. Esses arquivos guardam uma rica herança da maior editora Suíça do século 18 , que permite ganhar uma compreensão incomum da ideia de como os livros eram feitos e difundidos no século 18. Através dos anos, você leu todas as 50 mil cartas e outros documentos guardados naquele arquivo. Essas fontes forneceram um ponto inicial para muitos de seus projetos, entre outras coisas para o seu estudo detalhado da publicação da história da Encyclopédie, que oferece para nós, de certo modo, um entendimento do nível do dia a dia de como um enorme empreendimento foi realmente realizado. ${ }^{12}$ Poderia se dizer que você se tornou um historiador do livro graças a esses arquivos?

Quando visitei pela primeira vez os arquivos da Société typographique de Neuchâtel (STN), eu nunca tinha tido ouvido falar da história do livro. De fato, eu não acredito que a expressão existia naquele momento, nem em inglês e nem como "histoire du livre" ou "Geschichte des Buchwesens". Eu cheguei em Neuchâtel em 1965 para seguir o rastro do principal girondino da Revolução Francesa, Jacques-Pierre Brissot, que publicou a maior parte dos seus escritos pré-revolucionários com a STN. Depois de passar por algumas centenas de cartas, eu decidi que a história dos livros era mais interessante que a própria biografia de Brissot. E depois eu encontrei outros estudiosos que também procuravam entender a palavra escrita como uma força na história. Nós nos tornamos historiadores do livro sem conhecer algo como o modo que Monsieur Jourdain aprendeu que estava falando em prosa.
É claro que muitos estudiosos, especialmente bibliógrafos, tinham estudado livros muito antes de nós. Mas, uma vez que nós nos conhecemos uns aos outros, nós vimos que estávamos trabalhando através de novos problemas, novas formas; e no final nós tínhamos a sensação de estar contribuindo para a criação de uma nova disciplina. Eu penso que a história dos livros é agora mais saudável e o campo que cresce mais rapidamente dentro de todas humanidades.

Uma considerável divulgação do seu trabalho de pesquisa foi dedicada para a França do século 18 , sobre a literatura proibida. Graças a sua pesquisa, nós temos uma boa ideia da literatura que era secretamente lida pela maioria dos homens franceses, o que abrange, principalmente, os pretensos "livros filosóficos", forma que eram chamados naquele periodo isso é, escritos anticlericais e pornográficos. Você concluiu que foi a grande disseminação da literatura clandestina que teve um papel significante na força de arranque da Revolução Francesa. ${ }^{13}$ Essa é uma visão criticada, entre outros, pelo seu amigo Roger Chartier, no livro dele: Origens Culturais da Revolução Francesa, publicado recentemente em estoniano na mesma série do livro. Embora mais tarde você tenha especificado e explicado as suas visões, ${ }^{14}$ eu ainda gostaria de pedir para você retornar brevemente para o problema central desse argumento - os livros causam revoluções?

Roger primeiramente colocou a questão dessa forma durante um debate transatlântico que nós tivemos na France Culture, uma estação de rádio francesa. Apesar de não conseguir lembrar o que eu disse, lembro-me de pensar que é muito simples imaginar uma linha reta de causalidade - uma que leva da compra de livros à leitura de livros, até sua assimilação nas mentes dos leitores, para a opinião pública

\footnotetext{
Disponivel em: www.historycooperative.org/journals/ahr. Acesso em: 5 maio 2020.

DARNTON, Robert. The Business of Enlightenment: a publishing history of the Encyclopédie 1775-1800. Cambridge: Harvard University Press, 1968

13 DARNTON, Robert. The forbidden best-sellers of Pre-Revolutionary France. New York: W. W. Norton, 1995, p. $169-246$.

14 Ibidem, p. 169-246.
} 
como um fenômeno coletivo e finalmente para a ação. Todos os tipos de complicações e distorções colocados em muitos pontos da linha de transmissão. É provavelmente ilusório imaginar um processo linear, em primeiro lugar. Mas a questão permanece válida, se for formulada diferentemente: os livros têm um lugar na mistura complexa de elementos que podem ser estudados como causas? Eu penso que a resposta seja sim. Eu ainda acredito que é importante saber o que os franceses leram durante os vinte anos antes da Revolução, mesmo que nós não saibamos como eles leram.

Roger aceitou minhas procuras empíricas, mas depois recusou a sua importância, reivindicando que os leitores do século 18 poderiam ter desprezado as mensagens sediciosas da literatura libelle. ${ }^{15}$ Mas ele não produziu nenhuma evidência para provar essa asserção - nenhuma, exceto algum material de Mercier, que depois ele admitiu ser inadequado. No meu final, eu concordei que os libelles provavelmente eram lidos de diferentes maneiras - algumas sofisticadas e incrédulas, algumas inocentes e indignadas. Mas mesmo as sofisticadas - o marquês d'Argenson, por exemplo, ou Mme Roland, ou mesmo o próprio Mercier - absorveram muito da mensagem nessa literatura proibida e trabalharam em uma resposta mais complexa dos eventos de 1787 e 1788. Durante a crise pré-revolucionária, eu vejo um processo que eu chamo de "simplificação radical" - isso é, o desenho de linhas, para que as pessoas comuns se sentissem compelidas a tomar partido à favor ou contra o governo. É claro que as ideias desempenharam uma parte crucial no processo de alinhamento. Essas ideias incluiam noções abstratas desenvolvidas pelos filósofos Iluministas e argumentos complexos espalhados por protestos parlamentares. Todos os tipos de nuances ideológicas podem ser detectadas nos dois lados da grande divisão que separou os oponentes e os apoiadores do governo, durante esses anos críticos. Mas o aspecto mais importante da crise foi a própria divisão. Eu penso que as situações revolucionárias envolvem polarização: linhas são desenhadas, e a opinião pública se aglutina em posições básicas, como a oposição ou apoio aos homens no poder. A percepção dos eventos se torna tão importante quanto os próprios eventos, ou melhor, os dois não podem ser separados, pois os eventos perdem o controle e todo sistema é levado à violência.

Você pertence aos historiadores que contribuíram grandemente para o diálogo entre história e antropologia. Por muitos anos, você conduziu um seminário conjunto entre história e antropologia com Clifford Geertz na Universidade de Princeton, e você preferiu estabelecer a sua própria pesquisa sob o título de "antropologia histórica". A grande diferença entre um historiador e um antropólogo, de qualquer forma, reside no fato de que enquanto o primeiro estuda a cultura imediatamente, o segundo só pode fazer isso através da mediação de textos. Um dos seus livros recentes, trazendo junto as possibilidades da história e da antropologia, O Grande Massacre dos Gatos, ${ }^{16}$ não foi recebido apenas com grande reconhecimento e atenção, mas também com críticas partindo da própria questão, se os métodos da antropologia são aplicáveis no trabalho do historiador, com textos? ${ }^{17}$ Qual é a sua resposta para essa certa crítica e o que você pensa sobre as possibilidades de cooperação entre história e antropologia, no geral?

Essa questão me leva novamente para o meu argumento corrente com Roger Chartier. Na sua crítica do meu trabalho antropológico, ele reivindicou que seria possivel encontrar um informante nativo que poderia fornecer uma

Foi um gênero literário de panfleto político difamatório na França do Antigo Regime

DARNTON, Robert. The Great Cat Massacre and other episodes in French Cultural History. New York: Basic Books, 1984.

CHARTIER, Roger. Text, Symbols and Frenchness. Historical uses of Symbolic Anthropology. Journal of Modern History, Chicago, v. 57. p. $682-695,1985$

LACAPRA, Dominick. Darnton, and the Great Symbol Massacre. Journal of Modern History, Chicago, v. 60, p. 95-112, 1988.

HOURCADE, Eduardo; GODOY, Cristina; BOTALLA, Horacio (org.). Luz y contraluz de uma historia antropológica. Buenos Aires: Editorial Biblos, 1995. 
definição de simbolismo incompativel com a que eu usei - e que ele poderia rebaixar meu argumento antropológico pelos significados de uma técnica antropológica. Para esse fim, ele procurou por "símbolo" em um dicionário do século 18; observou uma definição de como uma coisa pode representar outra; e citou o exemplo do dicionário: o leão é um símbolo de valor. Na minha resposta, eu insisti que o dicionário do século 18 não fornecia uma noção adequada do simbolismo. Ele expressava uma visão do século 18, mas essa visão não poderia ser tomada como uma ferramenta conceitual que seria poderosa o suficiente para alavancar o mundo simbólico do século 18 de um homem francês. Para desenvolver uma aproximação antropológica adequada, é preciso consultar os conceitos de simbolismo desenvolvidos na teoria antropológica, não apenas por Clifford Geertz, mas também por Victor Turner, Mary Douglas, Keith Basso, Renato Rosaldo, Marshall Sahlins e muitos outros. Apesar de algumas discordâncias entre eles mesmos, nenhum deles inscreveu-se na simples ideia de que uma coisa representa a outra - um conceito que trabalha melhor em alguns estudos de alegoria, de qualquer forma, eles também tendem a ser complexos. Não, todos antropólogos insistem na multiplicidade, no caráter multivalente dos símbolos, na sua habilidade de transferir muitos diferentes significados, especialmente quando eles são usados em rituais.

No "Grande Massacre dos Gatos", eu tentei demonstrar a complexidade de associações simbólicas conectadas com os gatos. Eu também tentei mostrar como o ritual de matança dos gatos convergia com outros rituais no complexo padrão de comportamento - o julgamento e a execução de criminosos, a perseguição das bruxas, a performance nos teatros boulevard e o sexual braggadocio $^{18}$ dos homens. Esse argumento, que eu chamei de "ritual de punição", eu penso que não foi bem entendido pelos meus críticos. Mas aqueles que têm alguma familiaridade com a semiótica, têm reconhecido a natureza do meu argumento, muito mais do que aqueles que não concordam com ele. Dominique La Capra, quem você cita, é muito mais hostil a minha versão de história sociocultural do que Roger Chartier, mas ele aceita minha aproximação geral ao simbolismo. Depois ele tenta enfraquecer isso ao invocar as noções derivadas de Derrida. A minha instância teórica me coloca mais perto de Foucault. Então, alguém poderia identificar algum "maître à penser" que paira entre nós - e as contrastantes fontes de inspiração poderiam ser trabalhadas em algum ponto.

Hoje, de qualquer forma, essas disputas parecem datadas, e a própria antropologia deslocou-se para outras preocupações. Por um lado, ela se tornou mais histórica. Os antropólogos, frequentemente, realizam pesquisas em arquivos também como campo de trabalho, porque eles reconheceram o profundo, a dimensão temporal das culturas que estudam. A antiga distinção antropólogos estudam culturas separadas pelo espaço, historiadores estudam culturas separadas pelo tempo - não mais se sustenta e nunca se sustentou para antropólogos como Cliford Geertz. Então, eu continuo a acreditar na fecundidade de estudos que combinam antropologia e história, mesmo que o campo tenha mudado muito durante os últimos vinte anos, desde a publicação do "Grande Massacre dos Gatos".

Você estudou minuciosamente a França do Antigo Regime e o seu colapso na Revolução. Nos anos de 1989 até 1990, de qualquer forma, você mesmo, inesperadamente, teve a chance de testemunhar o colapso de outro Antigo Regime através dos eventos revolucionários. Por acaso, você passou o ano acadêmico de 1989/1990 no Leste de Berlim, onde em vez de escrever outra monografia do século 18 , você tomou nota dos eventos correntes. Essas notas se tornaram base para o seu jornal em Berlim, que brilhantemente expôs a natureza do regime alemão do Leste e registrou sua decomposição. ${ }^{19}$ Em conexão com esse livro, 
eu gostaria de perguntar o que, na sua visão, deveriam ser as relações do historiador com o seu período contemporâneo? Deveria a história ser escrita primariamente a fim de ganhar um melhor entendimento de seu próprio tempo?

Eu preciso confessar que penso que nós deveriamos estudar história para poder compreender o passado, não o presente. Eu não acredito que a história ensine lições. Eu acredito que fornece perspectiva - isso é, que nos ajuda a enxergar o presente em relação com os outros tempos e lugares. Isso pode nos dar uma profunda sensação da condição humana, e nos ajudar a impedir o tempo limitado, tendências etnocêntricas, que prejudicam todos esforços para entender o mundo em que nós vivemos. Todos nós, eu suspeito, tomamos o mundo que habitamos, aqui e agora, como praticamente imutável. A realidade que encontramos e construímos na nossa vida cotidiana, parece para nós ser fundamental. As coisas são da maneira que são, inescapáveis, como a morte e os impostos. Mas esse ponto de vista, que permitiu que nós deslizássemos dentro sem notar, está errado: história mostra que está errado.

Eu certamente não esperava que a Guerra Fria terminasse em Berlim no ano de 1989. Mas eu vi acontecer. Mesmo que eu não pudesse prever, isso confirmou que as coisas não são imutáveis, que as categorias fundamentais do dia a dia não são fixas, e que o mundo pode ser refeito - não completamente, é claro, não sem a continuidade do passado e não sem os desapontamentos que se colocam depois que o barulho para e a sujeira se instala. Mas as coisas podem desmoronar, e as partes vão se recombinar em novas configurações, às vezes, em concordância com algum grau da vontade humana. Isso é uma "lição"? Eu penso que não, mas eu recentemente vi um filme, "Sob a Névoa da Guerra" (The Fog of War), estrelando Robert McNamara, o secretário de defesa durante a Guerra do Vietnã. Ele descreveu o encontro com um alto oficial do antigo Vietcong muitos anos depois do fim da guerra, quando os dois eram idosos. McNamara observou, em retrospectiva, que todo o massacre poderia ter sido evitado, pois depois ficou claro que cada lado poderia ter concedido o que o outro queria. O oficial respondeu, salientando, que os americanos falharam em captar um fato fundamental sobre os seus inimigos: os vietnamitas nunca teriam se tornado um estado fantoche da China Comunista; eles teriam resistido à opressão chinesa por séculos. McNamara não saberia disso? Ele não teria estudado história? A resposta, é claro, era: não.

As suas opiniões recentes acerca do futuro dos livros deram origem a uma discussão pública animada. ${ }^{20}$ Embora você não tenha se juntado às fileiras daqueles que profetizam a iminente morte do livro tradicional, você experimentou as novas possibilidades de escrita e publicação oferecidas pela era eletrônica. Você publicou uma versão eletrônica de um pequeno estudo no século 18 parisiense, "information society"21 que habilmente emprega novos significados tecnológicos, como as imagens, mapas, trilhas sonoras e fontes. Agora, por muitos anos, você tem trabalhado numa monografia eletrônica compreensiva na literatura clandestina do século 18 na França, onde você tenta fazer o uso de todas oportunidades oferecidas por um novo meio. Como você resume suas experiências no campo de escrita de $e$-books e você vê os $e$-books como inevitáveis no futuro dos pesquisadores?

As economias de publicação parecem agora condenar algumas formas de publicação acadêmica, notavelmente monografias em

DARNTON, Robert. The new Age of the Book. The New York Review of Books, New York. Disponivel em: https://www.nybooks.com/ articles/1999/03/18/the-new-age-of-the-book. Acesso em: 26 mar. 2020.

DARNTON, Robert. A Historian of Books, Lost and Found in Cyberspace. The Chronicle of Higher Education. Washington, D.C. Disponivel em: https://www.chronicle.com/article/A-Historian-of-Books-Lost-and/11288. Acesso em: 25 mar. 2020.

DARNTON, Robert. No Computer Can Hold the Past. The New York Times, New York. Disponivel em: https://www.nytimes. com/1999/06/12/opinion/no-computer-can-hold-the-past.html. Acesso em: 25 mar. 2020.

${ }^{21}$ DARNTON, Robert. An Early Information Society: news and the media in eighteenth-century Paris. The American Historical Review, Oxford, v. 105, p. 1-35, 2000

BRISSOT, J.-P. Brissot, his career and correspondence (1779-1787). Oxford: Voltaire Foundation, 2001. 
áreas como: África colonial, história da América Latina. Muitos outros fatores alimentam essa situação, e eles estiveram nesse trabalho por muito tempo, de forma que eu penso que a monografia esotérica não vai sobreviver, ao menos não na escala que existiu de dez até trinta anos atrás. Livrarias, jornais, toda a estrutura da vida acadêmica está mudando; e a publicação acadêmica deve mudar com isso. Isso não significa que o códice venerável está morto. Ao contrário, mais volumes impressos são produzidos agora do que nunca. Mas as editoras universitárias reduziram a produção em certas áreas de tal forma que os jovens acadêmicos não conseguem entrar na mídia impressa - e nos Estados Unidos precisam romper a barreira da impressão para conseguirem suas carreiras. Enquanto isso, de qualquer forma, todos os tipos de formas eletrônicas de publicação foram desenvolvidos, incluindo um programa que eu iniciei enquanto presidente da Associação Americana de História: Gutenberg-e. Apesar de algumas dificuldades iniciais (principalmente atrasos no caminho), o programa provou ser um sucesso. Um programa relacionado, patrocinado pelo American Council of Learned Societies, History-e, também parece estar tendo sucesso - e sucesso comercial, porque os dois programas se tornaram autossustentáveis depois de receber suporte suficiente da Fundação Andrew W. Mellon para o seu início. Portanto, é possivel dar um relatório modesto, positivo sobre a nossa experiência com a publicação acadêmica por meio da internet. Nós fizemos o suficiente disso para saber que é viável. Isso é a resposta para tudo? Não: eu penso que os leitores vão continuar a aproveitar o livro tradicional da forma tradicional. $\mathrm{O}$ entusiasmo triunfal dos estágios iniciais de experimentação da publicação eletrônica evaporou-se, e agora estamos lidando com projetos viáveis.

O meu próprio trabalho, como você mencionou, inclui uma tentativa de produzir livros eletrônicos em larga escala sobre o assunto da publicação e da troca de livros na França e na Suiça do século 18. Ele incluirá uma vasta quantidade de arquivos e material visual, e os leitores poderão usá-lo de muitas formas. Eu espero que eles leiam da maneira tradicional de narrativa, horizontalmente, por assim dizer. Mas eles também poderão lêlo verticalmente - ou seja, clicar em camadas sucessivas de minimonografias e dados. Dessa forma, os leitores vão criar seus caminhos pessoais através do material. Graças aos avanços técnicos na indústria de impressão, eles poderão imprimir e encadernar seu próprio livro de bolso em uma questão de minutos e lê-lo no conforto das suas poltronas ou da maneira que desejarem. Esse tipo de livro irá criar uma nova relação entre leitor, autor, um novo tipo de leitura, um tipo que empodera o leitor, tornando ele ou ela, um colaborador e crítico do autor, abrindo inúmeras possibilidades para alargar o nosso entendimento do passado.

Existe um aspecto do códex convencional que eu rejeito: no caso da história dos livros, isso dá a impressão que temos a história sob controle, "debaixo de cobertores", embalada em segurança entre capas, fixada na impressão. Qualquer um que passou muito tempo nos arquivos, desenvolve a impressão oposta: nós mal começamos a captar a história; a maioria dos seres humanos morreu sem deixar vestígios da sua existência, e os vestígios que sobrevivem milhões de documentos espalhados por milhares de arquivos e sótãos - foram raramente lidos. Tomado pela solidez do livro bem acabado, nós vivemos com a ilusão de que temos uma boa compreensão do passado. Eu acho que a maior parte escapou entre os nossos dedos ou repousa além do nosso alcance. O livro eletrônico deve promover uma forma de capturar alguma experiência humana perdida. Isso irá aumentar o nosso conhecimento, certamente, mas também aguçará a nossa consciência de quão pouco nós sabemos. Isso, também, é uma lição do que podemos aprender com a história.

\section{Lucas de Oliveira Klever}

Mestrando em História pela Pontificia Universidade Católica do Rio Grande do Sul (PUCRS, Porto Alegre, RS, Brasil). 


\section{Endereço para correspondência}

Lucas de Oliveira Klever

Pontifícia Universidade Católica do Rio Grande do Sul

Av. Ipiranga, 6.681, prédio 8

Partenon, 97010-082

Porto Alegre, RS, Brasil. 